\title{
Hazardous alcohol use and associated factors in a rural Ethiopian district: a cross-sectional community survey
}

\author{
Solomon Teferra" ${ }^{1 *}$, Girmay Medhin², Medhin Selamu1', Arvin Bhana ${ }^{3}$, Charlotte Hanlon ${ }^{1,4}$ and Abebaw Fekadu ${ }^{1,5}$
}

\begin{abstract}
Background: Alcohol related health and social problems are on the rise in sub-Saharan Africa. This survey reports the prevalence and associated factors for hazardous drinking in rural Sodo district, southern Ethiopia. The survey was part of a multi-center study, Programme for Improving Mental Health Care (PRIME), which is a consortium of research institutions and ministries of health of five low and middle income countries, namely Ethiopia, India, Nepal, South Africa and Uganda in partnership with UK institutions and World Health Organization (WHO).

Methods: A cross-sectional community survey was conducted involving 1500 adults, age 18 and above, recruited using multi-stage random sampling. Data on alcohol use was collected using the Fast Alcohol Screening Test (FAST). Standardised instruments were used to measure potential associated factors, including a validated adaptation of the Kessler 10 (psychological distress), the List of Threatening Experiences (number of adverse life events). Exploratory multivariable logistic regression was conducted to examine factors associated with hazardous alcohol use.
\end{abstract}

Results: The overall prevalence of hazardous alcohol use was found to be $21 \% ; 31 \%$ in males and $10.4 \%$ in females, $P<0.05$. Factors independently associated with hazardous alcohol use were being male (adjusted $\mathrm{OR}=4.0$, $95 \% \mathrm{Cl}=2.44,6.67$ ), increasing age, having experienced one or more stressful life events (adjusted $\mathrm{OR}=1.71$, $95 \% \mathrm{Cl}=1.18,2.48$, and adjusted $\mathrm{OR}=2.12,95 \% \mathrm{Cl}=1.36,3.32$ for $1-2$ and 3 or more adverse life events, respectively) and severe psychological distress (adjusted $\mathrm{OR}=2.96,95 \% \mathrm{Cl}=1.49,5.89$ ). High social support was found to be protective from hazardous alcohol use (adjusted $O R=0.41,95 \% \mathrm{Cl}=0.23,0.72$ ).

Conclusion: High level of hazardous alcohol use was detected in this predominantly rural Ethiopian setting. The finding informed the need to integrate services for hazardous alcohol use such as brief intervention at different levels of primary care services in the district. Public health interventions to reduce hazardous alcohol use also need to be launched.

Keywords: Alcohol, Cross-sectional, Community survey, Hazardous use, Rural, Sub-Saharan Africa, Ethiopia

\section{Background}

Consumption of alcoholic beverages is a common practice among adults globally. Some of the consumption patterns may surpass acceptable limits and result in multitude of problems, including physical health, psychological and social problems. Around $4.9 \%$ of the

\footnotetext{
* Correspondence: soloteferra@yahoo.com

'Department of Psychiatry, College of Health Sciences, Addis Ababa University, Addis Ababa, Ethiopia

Full list of author information is available at the end of the article
}

world's adult population is believed to suffer from alcohol use disorder [1]. Besides the direct harm caused by alcohol such as liver injury, it is also an important risk factor for many chronic diseases, notably high blood pressure and other cardiovascular diseases related morbidity and mortality [2]. It is also an important risk factor for injury related morbidity and mortality. The World Health Organization (WHO) reports indicate that the global alcohol related mortality from cancer, liver cirrhosis and injury accounted for $2.8 \%$ of all deaths, $1.3 \%$ for women and $4.1 \%$ for men globally [3]. 
Although there is a dearth of prevalence studies in Africa, the existing literature indicates that alcohol use disorders are common. Evidence from an upper middleincome country in sub-Saharan Africa, South Africa (SA), showed that $9 \%$ of the population aged 15 years or older engaged in risky or hazardous or harmful drinking. More men had risky use than women, $17 \%$ and $2.9 \%$ respectively [4]. Another study done in a general outpatient population in different hospitals in SA involving 1,532 adults using Alcohol Use Disorder Identification Test (AUDIT) [5] found that $41.2 \%$ of men and $18.3 \%$ of women had hazardous drinking and $3.6 \%$ of men and $1.4 \%$ of women met criteria for probable alcohol dependence or harmful drinking as defined by AUDIT [6]. In another study in SA that looked at the burden of disease attributable to alcohol in 2000, $7.1 \%$ of all deaths in SA were attributed to alcohol. It also accounted for $7 \%$ of the total disability adjusted life years (DALYs). The two most important causes of alcohol related death were injury and cardiovascular incidents [7].

According to the 2011 Demographic and Health Survey (DHS) report by Central Statistics Authority (CSA) of Ethiopia, a national survey involving a representative sample from the age group 15-49 year old, $45 \%$ of women and $53 \%$ of men reported a history of alcohol consumption in their life time, $48 \%$ of women and $53 \%$ men of ever drinkers reported consumption of alcohol six or more days in the past month. Consumption rate was higher in urban areas, and the rates increased with age for both men and women [8].

Homemade alcoholic beverages include tella (local beer with alcohol content 2-4\%), tej (honey wine with alcohol content 7-11\%) and araqe (strong distilled liquor with alcohol content up to $45 \%$ ) [9], these beverages are consumed at home or in small traditional bars, 'tella bet' and 'araqe bet' meaning tella house and araqe house, where rural farmers and people in the lower socioeconomic status go to satisfy their needs. Most people consume these alcoholic beverages during traditional ceremonies, holidays or while taking respite from farm activities, but it is also common to consume these beverages during market days. Farmers who go to the market to sell their goods will normally end up drinking in the small bars which sell alcoholic beverages [9].

Prevalence Studies done in different parts of Ethiopia using the four-item "CAGE" screening questionnaire [10] have shown that hazardous alcohol drinking was $3.7 \%$ and $2.7 \%$ in rural and urban areas respectively $[11,12]$. In another study carried out in a semi-nomadic population in Southern Ethiopia using a structured diagnostic interview, the Composite International Diagnostic Interview (CIDI), the prevalence rate of alcohol dependence was $1.6 \%$, more in men than women, $3.7 \%$ and
$0.1 \%$ respectively [13]. Alcohol consumption has also been found to be associated with risky sexual behaviors and injuries in the Ethiopian context. For instance, a large study done in Addis Ababa involving in-school and out-of-school youth found significantly increased risky sexual behavior in youth who consumed alcohol and khat, an amphetamine-like stimulant [14].

This survey was part of a multi-center study, Programme for Improving Mental Health Care (PRIME), which is a consortium of research institutions and ministries of health of five low and middle income countries, namely India, Ethiopia, Nepal, South Africa and Uganda in partnership with UK institutions and World Health Organization (WHO) [15]. PRIME aims to generate evidence on approaches of integrating mental healthcare into primary care for selected priority disorders, including alcohol used disorders (AUD). In Ethiopia PRIME is being implemented in the Sodo District, a predominantly rural district in South Ethiopia. This study reports the prevalence of hazardous alcohol use and associated factors to inform the PRIME district level intervention.

\section{Methods}

A cross-sectional survey of adults aged 18 years and above was conducted. Participants were selected randomly from all sub-districts (kebeles) of the Sodo district proportional with the population size of each sub-district.

\section{Participants and setting}

Sodo district, a predominantly rural district, is located in the Gurage Zone, Southern Nations, Nationalities and Peoples Region (SNNPR), $100 \mathrm{~km}$ south of the capital of Ethiopia, Addis Ababa. The population of the district is 161,952 persons (79,356 men; 82,596 women) living in 58 sub-district [16]. Different ethnic groups live in the district: Sodo Gurage (85.3 \%), Oromo (11.6\%) and Amhara $(1.5 \%)$ and others (1.6 \%). The lingua franca, Amharic, is also the working language in the district. The majority follows the Coptic Orthodox Christian faith (97\%) and Muslims make up $2.3 \%$. The district has 62 health facilities, all at the level of primary healthcare: 8 public and 1 run in a public private partnership arrangement and more than 50 health posts in the community, all government owned, run by 2 female health extension workers who have a high school education plus one year training in preventive, promotive and very basic curative services. The health center in Bu'i, the district capital, is undergoing upgrading to get the status of a rural hospital. The nearest hospital is located in Butajira town, $30 \mathrm{~km}$ South of Bu'i town. Mental health care provision is being started in the district with the help of the PRIME project. Prior to this service being initiated by PRIME, people with mental and substance use disorders had to travel to Butajira hospital, which has a psychiatric 
nurse led outpatient service or go to the capital Addis Ababa to receive mental health services. PRIME was launched in Sodo because the district was believed to represent rural Ethiopia and is located close to the capital city where specialist mental health services exist and is linked to the Butajira Demographic Surveillance Site, DSS, which has research infrastructure $[17,18]$.

Inclusion criteria were being aged 18 years and above, able to give consent and residing in the particular subdistrict for six or more months.

\section{Sampling method}

Multistage sampling method was used. First, the number of households in each sub-district was determined. After samples of households were calculated from each subdistrict, participants were selected proportionate to the number of households in each sub-district. Consequently, the number of adults included in the study was equal to the number of households selected in each subdistrict. When there were more than one eligible adult in a household, the sample was selected using random sampling. The total sample size was 1,500 , determined based on the assumption of prevalence of $10 \%$ (a conservative estimate) and a design effect of $1.5 \%$, a precision of $0.02 \%$ and a non response rate of $15 \%$.

\section{Screening for alcohol use disorder}

Screening for alcohol use was carried out using the Fast Alcohol Screening Test (FAST), a short screening questionnaire for hazardous drinking comprising four questions which can be easily administered in a minute or less, derived from Alcohol Use Disorder Identification Test (AUDIT) $[5,19]$. The items in FAST include the following questions: 1) MEN: How often do you have EIGHT or more drinks on one occasion? WOMEN: How often do you have SIX or more drinks on one occasion? (Score: $0=$ Never, $1=$ Less than Monthly, $2=$ Monthly, 3 = Weekly, 4 = Daily or almost daily). 2) How often during the last year have you been unable to remember what happened the night before because you had been drinking? (Score: $0=$ Never, $1=$ Less than Monthly, $2=$ Monthly, $3=$ Weekly, $4=$ Daily or almost daily). 3) How often during the last year have you failed to do what was normally expected of you because of drinking? (Score: $0=$ Never, $1=$ Less than Monthly, $2=$ Monthly, $3=$ Weekly, $3=$ Daily or almost daily). 4) In the last year has a relative or friend, or a doctor or other health worker been concerned about your drinking or suggested you cut down? (Score: $0=\mathrm{No}, 2=$ Yes, on one occasion, $4=$ Yes, on more than one occasion). A score of 3 or more out of 16 indicates the occurrence of hazardous alcohol use [20,21], a pattern of drinking which is associated with increased risk of adverse psychological or physical consequences in the future [21]. The FAST has been found to have better psychometric properties than the CAGE $[22,23]$, with sensitivity of 0.93 and specificity of 0.88 [20], and comparable to the AUDIT [24]. It is also reported to have a higher sensitivity and specificity than the AUDIT when used in emergency departments [24]. Although not validated in the Ethiopian setting, the AUDIT has been validated in neighbouring African countries [25, 26]. Local alcoholic beverages were converted into standard equivalent alcohol units when reported by the respondents using different containers such as flasks, cans and glasses. Estimates of the alcohol content of the different locally available beverages has been determined before and used to estimate the amount of alcohol units consumed [9].

Psychological distress was assessed using the Kessler Psychological Distress Scale (K-10) [27]. List of Threatening Experiences (LTE), with 12 categories of adverse life events, was used for assessing stressful life experiences in the past six months. Examples of items in the LTE include death of close persons, loss of relationships, imprisonment, and being the victim of theft [28]. The Oslo-3 Social Support Scale (OSS-3), a three item scale exploring the number of close confidants, perceived level of concern from others and perceived ease of getting help from neighbours, was used to assess social support [29].

\section{Administration of assessment instruments}

The FAST alcohol screening questionnaire was part of the screening instruments compiled to collect information on a range of mental health and related issues in the PRIME Project in Sodo. Trained community health workers administered the questionnaire translated to the local language of Amharic. The supervisors of data collectors were nurses who had many years of experience working in mental health research.

\section{Data analysis}

Data was entered using Epi-data version 3.1 and analyzed using SPSS-20 (IBM Corp 2012) respectively. Using descriptive methods, the data was summarized, prevalence of hazardous alcohol use was determined and odds ratios (OR) were obtained using logistic regression. The effect of Sociodemographic (age, sex, education, marital status, occupation, residence, ethnicity, and perceived relative wealth) and psychosocial factors (social support, life events, mental distress) on hazardous drinking was explored using crude and adjusted odds ratios.

\section{Ethical considerations}

Ethical approval was obtained from the Institutional Review Board of the College of Health Sciences of Addis Ababa University. Participants gave their written informed consent after adequate information about the study, and the potential benefits and risks, had been provided. 


\section{Results}

\section{Socio-demographic characteristics}

A total of 1,500 participants were interviewed, of whom $49.5 \%$ were males. Ninety percent of the participants resided in rural areas. Farming was reported to be the occupation by $51.6 \%$ of the participants, being housewife was the predominant occupation reported by the women and $8.7 \%$ of the respondents reported to be engaged in private business. The majority belong to the Gurage Ethnic group $(94.6 \%)$. More than $90 \%$ were aged below 60 years, and more than $75 \%$ were married. Regarding literacy, $42.8 \%$ were illiterate, $23.8 \%$ able to read and write, $24.5 \%$ primary education, only $8.8 \%$ had secondary and above education. Close to $90 \%$ described their income as average or low relative to others in their neighbourhood, taken as a crude estimate of wealth.

The overall prevalence of hazardous alcohol use was found to be $21 \%, 31 \%$ in males and $10.4 \%$ in females, $P<0.05$. Forty two percent of respondents reported experiencing one or more life events in the past six months. Similarly, nearly $41.9 \%$ described their social support as poor, and only $11.7 \%$ reported to have strong social support. Regarding the findings on psychological distress as measured by the Kessler-10 psychological distress scale, $13.9 \%, 9.0 \%$, and $5.2 \%$ scored mild, moderate and severe respectively.

Details of the socio-demographic and clinical characteristics are presented in Table 1.

\section{Hazardous alcohol use and associated factors}

Table 2 shows the result of logistic regression analysis of the different factors and their association with hazardous alcohol use; both crude and adjusted results were calculated and reported. Males had significantly increased risk of hazardous alcohol use both in the crude and adjusted analysis (adjusted $\mathrm{OR}=4.0,95 \% \mathrm{CI}=2.44,6.67, P<0.05$ ). All of the age groups 25 years or older had significantly higher rates of hazardous alcohol use in the crude analysis; whereas, difference was not significant for age group 60 and above in the adjusted analysis. Number of adverse life events was significantly associated with hazardous alcohol use both in crude and adjusted analysis (adjusted $\mathrm{OR}=1.71,95 \% \mathrm{CI}=1.18$, $2.48, P<0.05$ and adjusted $\mathrm{OR}=2.12,95 \% \mathrm{CI}=1.36$, 3.32, $P<0.05$ for $1-2$ and 3 or more adverse life events respectively). The other factors significantly associated with hazardous alcohol use was severe psychological distress (adjusted $\mathrm{OR}=2.96,95 \% \mathrm{CI}=1.49$, 5.89, $P<0.05)$. High social support was found to be protective from hazardous alcohol use in the adjusted analysis (crude $\mathrm{OR}=0.64,95 \% \mathrm{CI}=0.40,1.01$, adjusted $\mathrm{OR}=0.41, \quad 95 \% \quad \mathrm{CI}=0.23, \quad 0.72, \quad P<0.05)$.
Table 1 Socio-demographic and clinical characteristics of participants in Sodo, Southern Ethiopia

\begin{tabular}{|c|c|c|}
\hline \multicolumn{2}{|l|}{ Characteristics } & \multirow{2}{*}{$\frac{\text { Number (\%) }}{742(49.5)}$} \\
\hline Sex & Male & \\
\hline & Female & $758(50.5)$ \\
\hline \multirow[t]{5}{*}{ Age group (years) } & $18-24$ & $224(15.1)$ \\
\hline & $25-34$ & $425(28.6)$ \\
\hline & $35-44$ & $395(26.6)$ \\
\hline & $45-49$ & $322(21.6)$ \\
\hline & 60 and above & $122(8.2)$ \\
\hline \multirow[t]{3}{*}{ Marital status } & Single & $260(17.5)$ \\
\hline & Married & $1129(75.8)$ \\
\hline & Divorced/Widowed & $100(6.7)$ \\
\hline \multirow[t]{4}{*}{ Education } & Illiterate & $592(42.9)$ \\
\hline & Able to read & $328(23.8)$ \\
\hline & Primary & $338(24.5)$ \\
\hline & Secondary and above & $122(8.8)$ \\
\hline \multirow[t]{2}{*}{ Residence } & Urban & $139(9.3)$ \\
\hline & Rural & $1352(90.7)$ \\
\hline \multirow[t]{2}{*}{ Ethnicity } & Gurage & $1414(94.6)$ \\
\hline & Other & $81(5.4)$ \\
\hline \multirow[t]{5}{*}{ Occupation } & Farmer & 770 (51.6) \\
\hline & Housewife & $405(27.1)$ \\
\hline & Private business & $130(8.7)$ \\
\hline & Daily laborer & $75(5.0)$ \\
\hline & Other & $113(7.6)$ \\
\hline \multirow[t]{3}{*}{ Perceived relative wealth } & Poor & $499(34.1)$ \\
\hline & Average & $796(54.4)$ \\
\hline & High & $168(11.5)$ \\
\hline \multirow[t]{2}{*}{ Hazardous alcohol use } & Male & $230(31.8)$ \\
\hline & Female & 79 (10.4) \\
\hline \multirow[t]{3}{*}{ Number of adverse life events } & No life event & $769(58.0)$ \\
\hline & $1-2$ events & $343(25.9)$ \\
\hline & $\geq 3$ events & $214(16.1)$ \\
\hline \multirow[t]{3}{*}{ Social support } & Poor & $581(41.9)$ \\
\hline & Moderate Support & $644(46.4)$ \\
\hline & Strong support & $162(11.7)$ \\
\hline \multirow[t]{4}{*}{ Severity of psychological distress } & No distress & $1059(71.9)$ \\
\hline & Mild & $204(13.9)$ \\
\hline & Moderate & $133(9.0)$ \\
\hline & Severe & $76(5.2)$ \\
\hline
\end{tabular}

Marital status and level of literacy were not significantly associated with hazardous alcohol use. Similarly, place of resident, ethnicity, occupation and perceived relative wealth were not significantly associated with hazardous alcohol use. 
Table 2 Sociodemographic and clinical factors associated with hazardous use of alcohol in Sodo, Southern Ethiopia

\begin{tabular}{|c|c|c|c|c|c|c|}
\hline \multicolumn{2}{|l|}{ Characteristics } & \multirow{2}{*}{$\frac{\text { Crude OR }}{4.0}$} & \multirow{2}{*}{$\frac{95 \% \mathrm{Cl}}{3.03-5.26}$} & \multirow{2}{*}{$\begin{array}{l}\text { Adjusted OR } \\
4.0\end{array}$} & \multirow{2}{*}{$\frac{95 \% \mathrm{Cl}}{2.44-6.67}$} & \multirow{2}{*}{$\frac{P \text {-value }}{<0.001}$} \\
\hline Sex & Male & & & & & \\
\hline & Female & Ref & & & & \\
\hline \multirow[t]{5}{*}{ Age group (years) } & $18-24$ & Ref & & & & \\
\hline & $25-34$ & 1.78 & $1.08,2.94$ & 2.05 & $1.03,4.09$ & 0.041 \\
\hline & $35-44$ & 2.82 & $1.73,4.59$ & 2.59 & $1.29,5.21$ & 0.007 \\
\hline & $45-59$ & 3.42 & $2.08,5.61$ & 3.26 & $1.59,6.67$ & 0.001 \\
\hline & $\geq 60$ & 2.30 & $1.24,4.27$ & 1.58 & $0.67,3.75$ & 0.295 \\
\hline \multirow[t]{3}{*}{ Marital status } & Single & Ref & & & & \\
\hline & Married & 1.32 & $0.93,1.87$ & 1.27 & $0.75,2.15$ & 0.374 \\
\hline & Divorced/widowed & 0.62 & $0.31,1.23$ & 0.63 & $0.24,1.64$ & 0.345 \\
\hline \multirow[t]{4}{*}{ Education } & Non-literate & Ref & & & & \\
\hline & No formal education but read and write & 2.11 & $1.52,2.92$ & 1.34 & $0.88,2.04$ & 0.177 \\
\hline & Primary education & 1.42 & $1.01,2.00$ & 0.98 & $0.61,1.59$ & 0.947 \\
\hline & Secondary and above & 1.42 & $0.86,2.32$ & 0.95 & $0.45,2.00$ & 0.886 \\
\hline \multirow[t]{2}{*}{ Residence } & Urban & Ref & & & & \\
\hline & Rural & 1.90 & $1.13,3.17$ & 1.94 & $0.90,4.21$ & 0.092 \\
\hline \multirow[t]{2}{*}{ Ethnicity } & Gurage & Ref & & & & \\
\hline & Others & 0.40 & $0.19,0.85$ & 0.45 & $0.19,1.08$ & 0.073 \\
\hline \multirow[t]{5}{*}{ Occupation } & Farmer & Ref & & & & \\
\hline & Housewife & 3.02 & $2.13,4.26$ & 1.10 & $0.65,1.86$ & 0.735 \\
\hline & Private business & 1.32 & $0.74,2.34$ & 1.49 & $0.70,3.19$ & 0.299 \\
\hline & Daily laborer & 2.64 & $1.44,4.83$ & 2.00 & $0.90,4.47$ & 0.090 \\
\hline & Others & 0.92 & $0.47,1.81$ & 0.95 & $0.36,2.50$ & 0.916 \\
\hline \multirow[t]{3}{*}{ Perceived relative wealth } & Low & Ref & & & & \\
\hline & Average & 1.23 & $0.93,1.64$ & 1.22 & $0.84,1.77$ & 0.300 \\
\hline & High & 1.57 & $1.04,2.38$ & 1.56 & $0.91,2.67$ & 0.104 \\
\hline \multirow[t]{3}{*}{ Number of adverse life events } & None & Ref & & & & \\
\hline & $1-2$ events & 1.72 & $1.26,2.35$ & 1.71 & $1.18,2.48$ & 0.005 \\
\hline & $\geq 3$ events & 2.69 & $1.91,3.79$ & 2.12 & $1.36,3.32$ & 0.001 \\
\hline \multirow[t]{3}{*}{ Social support } & Low & Ref & & & & \\
\hline & Moderate & 0.88 & $0.67,1.16$ & 0.73 & $0.52,1.02$ & 0.068 \\
\hline & High & 0.64 & $0.40,1.01$ & 0.41 & $0.23,0.72$ & 0.002 \\
\hline \multirow[t]{4}{*}{ Severity of psychological distress } & No distress & Ref & & & & \\
\hline & Mild & 1.50 & $1.05,2.13$ & 1.26 & $0.80,2.00$ & 0.315 \\
\hline & Moderate & 1.86 & $1.24,2.79$ & 1.37 & $0.80,2.35$ & 0.257 \\
\hline & Severe & 2.47 & $1.51,4.06$ & 2.96 & $1.49,5.89$ & 0.002 \\
\hline
\end{tabular}

*significant at $P$-value of $<0.05$

\section{Discussion}

This study is one of the few studies on hazardous alcohol drinking reported from a rural setting in subSaharan Africa. We found high level of hazardous alcohol use in this rural community of Sodo district which is located in the Ethiopian central highlands where consumption of home brewed alcoholic beverages is common.
Previous studies on alcohol in Ethiopia mainly focused on people living in cities which generally reported lower rates of hazardous drinking using CAGE as a screening tool. For instance, the prevalence of hazardous drinking in Addis Ababa was reported to be 2.7 \% [12]. Other alcohol studies in rural Ethiopia involved a population of isolated islanders, located at central rift valley lakes, and semi-nomadic populations in Southern Ethiopia. The 
lifetime prevalence of alcohol dependence in these two areas was $1.5 \%$ and $1.6 \%$ respectively $[9,13]$. The report from the neighboring district of Butajira by Alem et al. was $3.7 \%$ [11], slightly higher than Addis Ababa but much lower than Sodo. One explanation for such huge difference could be that residents in Butajira predominantly follow Islam while those in the Sodo district follow the Coptic Orthodox Christian faith which generally tolerates some consumption of alcohol. The other explanation for the difference could be the types of psychoactive substances commonly consumed in the two districts. In Butajira, $50 \%$ of adults were found to be current chewers khat $[6,12]$; whereas, khat chewing is much less common in Sodo. Production of local alcoholic beverages is an important income earner for women in Sodo as well which makes it readily available for consumers. The rate of alcohol consumption in Sodo is generally believed to be somewhat similar to other nearby Christian highlanders; the central and northern highlands are predominantly populated by Christians. The other likely reason for the difference in prevalence is the measurement instruments that were used. CAGE generally picks up severe alcohol use disorder compared to FAST which was developed to assess hazardous drinking. A study done in four cities in the UK comparing CAGE with FAST found a sensitivity of $40 \%$ and $93 \%$ for picking hazardous drinking, respectively [21].

The finding from Sodo is the highest prevalence of hazardous alcohol use in Ethiopia reported thus far. Ethiopia has experienced economic boom in recent years which resulted in poverty reduction and economic improvement (www.worldbank.org/en/country/ethiopia). This has resulted in a substantial influx of foreign direct investment into the country. The largest investment from Europe into the country came from big breweries (www.thereporterethiopia.com/index.php/interview/item/1963-its-ethiopias-time). Currently, there is huge expansion of the beer industry with extensive promotion activities going on throughout the country. It is likely to reach a stage of an 'industrial epidemic' soon [30]. Although locally brewed alcoholic beverages are predominantly consumed in rural areas, manufactured beverages are increasingly gaining popularity. Nowadays, drinking manufactured liquor and beer is considered a status symbol. Hence, the findings in Sodo are pertinent to the rest of the country.

In this study, hazardous use of alcohol was also found to be associated with being male, age below 60 years, having experienced one or more life events and severe psychological distress. Substance abuse is generally more common in men than women, it is even more so in men living in sub-Saharan Africa where one would find much more abstaining women than men [4,31]. Although high rates of hazardous alcohol use is common in young people, usually in the form of binge drinking, this phenomenon was found to be less common in Africa compared to western countries [31, 32]. In this study, we found that the rate of hazardous alcohol use increased with increasing age till age 60 . Problems arising from excessive alcohol drinking are many; it is an important risk factor for many of the chronic diseases including neuropsychiatric disorders and considered to be among the top causes of global burden of disease, disability and premature death [33]. The presence of severe psychological distress was significantly associated with hazardous alcohol use in this study. This is consistent with studies reported from elsewhere. Although it is difficult to determine causality, it is common to find people who have underlying psychological problems to be more prone to drinking large quantities of alcohol possibly as self medication, or the hazardous use of alcohol may predispose users to psychological distress [34, 35]. Similarly, experiencing one or more adverse life events was also associated with hazardous alcohol use which was consistent with other findings [36].

Limitations in this study include possible underreporting by participants, but it is generally believed that people who drink alcohol report their alcohol intake in a reliable way [37]. The validity of such reports had been confirmed both in community surveys as well as in people who have alcohol dependence $[37,38]$. There could also be recall bias or difficulty understanding some of the items as well as issues with translation of the questions as the FAST instrument was not validated in Ethiopia. The possibility of overreporting due to social desirability or misunderstanding of the questions cannot be ruled out. Measurement bias is also another limitation when using an instrument which is not validated for use in a particular setting. Generally, the FAST instrument was validated as a quick screening instrument for hazardous alcohol use in emergency medical settings elsewhere and has been rarely used in community surveys.

\section{Conclusion}

In summary, the high rate of hazardous alcohol use that was found in this rural Ethiopian primary care setting warrants attention. Moreover, it affects productive members of the society which will have significant impact on families and the country as whole. Public health measures that aim at reducing hazardous alcohol use coupled with a stepped care approach for alcohol use disorder i.e. screening all adults presenting at primary care, brief intervention for hazardous drinking and referral of severe cases of alcohol dependence is recommended.

\section{Competing interests \\ The authors declare that they have no competing interest.}

Authors' contributions

$A F, C H, G M, A B$ contributed in the design of the study. MS supervised data collection. AF, GM and ST analyzed the data, and ST wrote the first draft. All authors reviewed the manuscript. 


\section{Acknowledgement}

The report in this study is part of the PRMIE project which has been funded by UK Aid, from the UK Government; however, the views expressed in the report do not necessarily reflect the UK Government's official policies. We gratefully acknowledge the support we received from the Sodo district health office, the district administration, the health extension workers who collected the data and the supervisors.

\section{Author details}

'Department of Psychiatry, College of Health Sciences, Addis Ababa University, Addis Ababa, Ethiopia. ${ }^{2}$ Aklilu Lemma Institute of Pathobiology, Addis Ababa University, Addis Ababa, Ethiopia. ${ }^{3}$ Health Systems Research Unit, South African Medical Research Council, School of Applied Human Sciences, University of KwaZulu-Natal , Durban, South Africa. ${ }^{4}$ King's College London, Institute of Psychiatry, Psychology and Neuroscience, Centre for Global Mental Health, London, UK. ${ }^{5}$ King's College London, Institute of Psychiatry, Psychology and Neuroscience, Centre for Affective Disorders, London, UK

\section{Received: 28 August 2015 Accepted: 26 February 2016} Published online: 03 March 2016

\section{References}

1. Gowing LR, Ali RL, Allsop S, Marsden J, Turf EE, West R, et al. Global statistics on addictive behaviours: 2014 status report. Addiction. 2015;110:904-19.

2. Parry CD, Patra J, Rehm J. Alcohol consumption and non-communicable diseases: epidemiology and policy implications. Addiction. 2011;106(10): 1718-24.

3. Rehm J, Shield KD. Global alcohol-attributable deaths from cancer, liver cirrhosis, and injury in 2010. Alcohol Res. 2013;35(2):174-83.

4. Peltzer K, Davids A, Njuho P. Alcohol use and problem drinking in South Africa: findings from a national population-based survey. Afr J Psychiatry. 2011;14:30-7.

5. Babor TF, Higgins-Biddle JC, Saunders JB, Monteir MG. The Alcohol Use Disorders Identification Test: Guidelines for Use in Primary Health Care. 2nd ed. Geneva: World Health Organization; 2001.

6. Pengpid S, Peltzer K, Van der Heever H. Prevalence of Alcohol Use and Associated Factors in Urban Hospital Outpatients in South Africa. Int J Environ Res Public Health. 2011;8:2629-39.

7. Schneider M, Norman R, Parry C, Bradshaw D, Pluddemann A, Group, SACRAC. Estimitaing the burden of disease attributable to alcohol use in South Africa in 2000. S Afr Med J. 2007;97:664-72

8. Central Statistical Agency [Ethiopia] and ICF International. Ethiopia Demographic and Health Survey 2011. Addis Ababa, Ethiopia and Calverton, Maryland, USA: Central Statistical Agency and ICF International; 2012.

9. Fekadu A, Alem A, Hanlon C. Alcohol and drug abuse in Ethiopia: past, present and future. Afr J Drug Alcohol Studies. 2007;6:39-53.

10. Smart RG, Adaf EM, Knoke D. Use of the CAGE scale in a population survey of drinking. J Stud Alcohol. 1991;52(6):593-6.

11. Alem A, Kebede D, Kullgren $G$. The epidemiology of problem drinking in Butajira. Ethiopia Act Psychiatr Scand. 1999;100:77-83.

12. Kebede $D$, Alem A. The epidemiology of problem drinking and alcohol deprendence in Addis Ababa. Act Psychiatr Scand. 1999;100:30-4.

13. Beyero T, Alem A, Kebede D, Shibire T, Desta M, Deyessa N. Mental disorders among the Borana semi-nomadic community in Southern Ethiopia. World Psychiatry. 2004;3:2.

14. Kebede D, Alem A, Mitike G, Enquselassie F, Berhane F, Abebe Y, et al. Khat and Alcohol Use and Risky Sex Behavior among In-school and Out of School Youth in Ethiopia. BMC Public Health. 2005;5:109.

15. Lund C, Tomlinson M, De Silva M, Fekadu A, Shidhaye R, Jordan M, et al PRIME: A Programme to Reduce the Treatment Gap for Mental Disorders in Five Low- and Middle-Income Countries. PLoS Med. 2012;9(12), e1001359.

16. Hanlon C, Luitel NP, Kathree T, Murhar V, Shrivasta S, Medhin G, et al. Challenges and opportunities for implementing integrated mental health care: a situation analysis from five low- and middle-income country districts. PLoS One. 2014;9(2), e88437.

17. Byass $P$, Berhane $Y$, Emmelin A, Kebede D, Andersson T, Högberg U, et al. The role of demographic surveillance systems (DSS) in assessing the health of communities: An example from rural Ethiopia. Public Health. 2002;116(3):145-50.
18. Shamebo D, Muhe L, Sandström A, Wall S. The Butajira Rural Health Project in Ethiopia: Mortality Pattern of the Under Fives. J Trop Pediatr. 1991;37(5):254-61

19. Hodgson R, Alwyn T, John B, Thom B, Smith A. The FAST Alcohol Screening Test. Alcohol Alcohol. 2002;37:61-6

20. Hodgson RJ, John B, Abbasi T, Hodgson RC, Waller S, Thom B, et al. Fast screening for alcohol misuse. Addict behave. 2003;28(8):1453-63.

21. Health Development Agency. Manual for the Fast Alcohol Screening Test. London: Health Development Agency; 2002.

22. Chan AW, Pristach EA, Welte JW. Detection by the CAGE of alcoholism or heavy drinking in primary care outpatients and the general population. J Subst Abuse. 1994;6(2):123-35.

23. Kelly TM, Donovan JE, Chung T, Bukstein OG, Cornelius JR. Brief screens for detecting alcohol use disorder among 18-20 year old young adults in emergency departments: Comparing AUDIT-C, CRAFFT, RAPS4-OF, FAST, RUFT-Cut, and DSM-IV 2-Item Scale. Addict Behav. 2009;34(8):668-74.

24. Meneses-Gaya C, Crippa JA, Zuardi AW, Loureiro SR, Hallak JE, Trzesniak C, et al. The fast alcohol screening test (FAST) is as good as the AUDIT to screen alcohol use disorders. Subst Use Misuse. 2010;45(10):1542-57.

25. Saunders JB, Aasland OG, Babor TF, de la Fuente JR, Grant M. Development of the Alcohol Use Disorders Identification Test (AUDIT). WHO Collaborative Project on Early Detection of Persons with Harmful Alcohol Consumption-II. Addiction. 1993:88:791-804.

26. Chishinga N, Kinyanda E, Weiss HA, Patel P, Ayles H, Seedat S. Validation of brief screening tools for depressive and alcohol use disorders among TB and HIV patients in primary care in Zambia. BMC Psychiatry. 2011:11:75.

27. Kessler RC, Andrews GLJC, Hiripi E, Mroczek DK. Short screening scales to monitor population prevalences and trends in non-specific psychological distress. Psychol Med. 2002;32:959-76.

28. Brugha T, Bebbington P, Tennant C, Hurry J. The List of Threatening Experiences: a subset of 12 life event categories with considerable long-term contextual threat. PsycholMed. 1985;15:189-94.

29. Dalgard OS, Dowrick C, Lehtinen V, Vazquez-Barquero JL, Casey P, Wilkinson $\mathrm{G}$, et al. Negative life events, social support and gender difference in depression: a multinational community survey with data from the ODIN study. Soc Psychiatry Psychiatr Epidemiol. 2006;41(6):444-51.

30. Jahiel RI, Babor TF. Industrial epidemics, public health advocacy and the alcohol industry: lessons from other fields. Addiction. 2007;102(9):1335-9.

31. Courtney KE, Polich J. Binge Drinking in Young Adults: Data, Definitions, and Determinants. Psychol Bull. 2009;135(1):142-56.

32. Obot IS. Alcohol Use And Related Problems In Sub-Saharan Africa. Afr J Drug Alcohol Studies. 2006;5(1):17-26.

33. Rehm J, Mathes C, Popova S, Thavorncharoensap M, Teerawattananon Y, Patra J. Global burden of disease and injury and economic cost attributable to alcohol use and alcohol-use disorders. Lancet. 2009;373(9682):2223-33.

34. Caldwell TM, Rodgers $B$, Jorm AF, Christensen $\mathrm{H}$, Jacomb PA, Korten AE, et al. Patterns of association between alcohol consumption and symptoms of depression and anxiety in young adults. Addiction. 2002;97(5):583-94.

35. Graham K, Massak A, Demers A, Rehm J. Does the Association Between Alcohol Consumption and Depression Depend on How They Are Measured? Alcohol Clin Exp Res. 2007;31(1):78-88.

36. Fox HC, Bergguist KL, Peihua G, Rajita S. Interactive effects of cumulative stress and impulsivity on alcohol consumption. Alcohol Clin Exp Res. 2010;34(8):1376-85.

37. Sobell LC, Maisto SA, Sobell MB, Cooper AM. Reliability of alcohol abusers' self-reports of drinking behavior. Behav Res Ther. 1979;17(2):157-60.

38. Williams GD, Aitkin SS, Malin H. Reliability of Self-Reported Alcohol Consumption in a General Population Survey. J Stud Alcohol. 1985;46(3):223-7. 